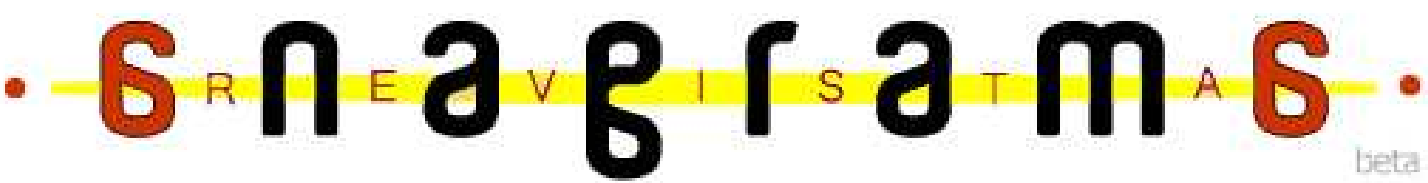

\section{Entre Castro Alues e Sebastião Salgado: o diálogo condoreiro}

\section{Camilla Cafuoco moreno ${ }^{1}$}

\section{Resumo}

O estudo pretende desenvolver o diálogo entre textos de natureza distinta, ou seja, o dialogismo entre o texto literário, verbal, romântico e o texto imagético fotodocumentarista. Utilizou-se como corpus de análise o poema de Castro Alves intitulado, Navio negreiro: tragédia no mar, mais especificamente as terceira e quarta partes e o conjunto de imagens captadas por Sebastião Salgado, pertencentes ao livro Trabalhadores: uma arqueologia da era industrial. A base teórica utilizada para o desenvolvimento do projeto compreende autores como Bakhtin, Kristeva, Fiorin e Barros, no que concerne à questão dialógica e intertextual; Gomes Filho, Dondis, Arnheim e Manguel, a fim de embasar a análise imagética; Lajolo, Campedelli e Bosi como suporte literário e Flusser, Souza e Guimarães para as questões fotográficas.

Palauras-chaue: Texto Verbal e Imagético; Condoreirismo; Dialogismo.

As idéias geradoras dos ideais do Romantismo tiveram como precursores países como Inglaterra, Alemanha e França que, juntamente com as concepções da Revolução Francesa, desempenharam o papel de expandir esse movimento artístico.

Com as influências das idéias medievais, a Natureza é retomada não como simples componente do cenário, mas, sim, como expressão do estado de espírito do eu-lírico, desta forma, tem-se uma Natureza escura quando o eu-lírico está deprimido e uma Natureza exuberante quando o eu-lírico está feliz.

A idéia de liberdade era um conceito que, nesta fase, fez-se muito presente, repercutindo na postura dos românticos que se rebelavam contra os ideais das formas e

\footnotetext{
${ }^{1}$ Aluna da graduação da Universidade Presbiteriana Mackenzie e professora da Escola de Idiomas CNA.
} 
regras pré-estabelecidas pela época anterior, o Arcadismo, portanto desejavam a manifestação da expressão artística por meio de uma escrita mais livre e sem formas determinadas.

Portugal aderiu ao Romantismo quase que simultaneamente ao nascimento deste movimento na França, no fim de 1820, com Vitor Hugo, uma vez que o marco inicial da literatura romântica portuguesa foi a publicação do poema Camões, em 1825, por Almeida Garrett.

A vinda da família real portuguesa, em 1808, e a posterior Independência brasileira, em 1822, geraram um surto nacionalista que tomou conta do Brasil. A idéia de nação, como sendo uma comunidade de indivíduos que, embora sob vários regimes políticos, são ligados por identidade de origem, língua, costumes, religião começou a se fazer presente, ou seja, exaltava-se tudo que era próprio da nação. O ufanismo, característica romântica, ocorreu no mundo inteiro, e no Brasil repercutiu como sendo uma característica marcante do movimento literário, assim sendo, o artista romântico brasileiro passou muito tempo buscando uma identidade nacional.

O Romantismo brasileiro encontrou manifestações literárias em prosa e em poesia. A prosa citadina ou urbana ficou representada por autores como Joaquim Manuel de Macedo, Manuel Antonio de Almeida e José de Alencar. Este último, também autor da prosa indianista, que tem como obras representantes, $O$ Guarani e Iracema. José de Alencar também contribuiu com a prosa regionalista, no qual, se destaca Visconde de Taunay, autor de Inocência.

A poesia romântica brasileira conheceu três grandes gerações. A primeira geração foi considerada como nacionalista ou indianista representado por Gonçalves de Magalhães e Gonçalves Dias. A segunda geração foi o ultra-romântico ou, também, mal-do-século representada por Álvares de Azevedo, Casimiro de Abreu e Fagundes Varela e, a terceira geração denominada poesia condoreira, teve como seus maiores representantes Sousândrade e Castro Alves, autor este, entre outros poemas, de Navio Negreiro: tragédia no mar, obra que, neste trabalho, dialoga com fotografias de Sebastião Salgado.

Diferentemente da primeira e segunda gerações da poesia romântica brasileira, a terceira geração, a qual pertence Castro Alves, demonstrou em seus versos um inconformismo e, some-se, o reformismo.

Em uma determinada região do nordeste, no caso, o Recife, alguns estudantes universitários colocavam em questão a problemática social em vigor, postura a qual foi 
revelada nos versos que eles elaboravam. A produção literária desse período foi chamada de social uma vez que defendia os ideais abolicionistas e da República e, foi denominada, também, hugoana, pois sofreu uma considerável influência do escritor romântico francês Victor Hugo, que também, destinava suas criações literárias às causas sociais. Esta geração ficou conhecida como condoreira. Nas palavras de Campedelli e Souza (1999, p.128) “A poesia abolicionista de Castro Alves demonstra que ele aprendeu muito bem o que ensina o 'mestre' francês Victor Hugo: a possibilidade de registrar artisticamente não o belo, mas também o grotesco."

O nome "condoreira" está diretamente ligado ao pássaro andino, condor. Essa nomenclatura foi eleita por Capistrano de Abreu. Este pássaro quando chega à fase adulta, atinge três metros de envergadura entre uma asa e a outra e seu vôo é muito alto, fato que representa claramente os ideais desses poetas, a liberdade. A caracterização dessa geração é tomada pelo estilo dramático, hiperbólico, exclamativo, cheio de inúmeras apóstrofes e representações metafóricas. Os poetas dessa geração tinham o intuito de fazer a poesia com a função de ser um instrumento de reforma social.

A maior representação dessa geração romântica brasileira foi o poeta Antônio Frederico Castro Alves, que nasceu a 14 de março de 1847, na região da Bahia. Sua poesia era estabelecida com uma função social muito bem demarcada, portanto a vocação para estas causas era nítida. Os poemas desse representante condoreiro deram forma à massa escrava oprimida, uma vez que revelaram dramas que eram profundos nas senzalas. Assim, Castro Alves despertou interesse e conseguiu apoio daqueles que estavam de acordo com a abolição.

Na visão de Alfredo Bosi

sua estréia coincide com o amadurecer de uma situação nova: a crise do Brasil puramente rural; o lento, mas firme crescimento da cultura urbana, dos ideais democráticos e, portanto, o despontar de uma repulsa pela moral do senhor-e-servo, que poluía as fontes da vida familiar e social no Brasil-Império. (BOSI, 1995, p.120),

Um de seus mais célebres poemas que tratam da escravidão intitula-se Navio Negreiro: tragédia no mar. Este é composto por seis partes, nas quais o poeta tenta representar a grande trajetória marítima do povo escravizado, trazendo à tona aspectos como a crueldade do tráfico negreiro, o martírio dos açoites, e o mais rigoroso de todos, a privação da liberdade dessas pessoas. 
É com terceira e quarta partes de Navio Negreiro: uma tragédia no mar que se pode estabelecer o diálogo com as fotografias que Sebastião Salgado captou em Serra Pelada, em 1986.

Na terceira parte, do Navio Negreiro: uma tragédia no mar, o poeta adentra o navio, fato antes, ainda, não ocorrido, pois o tumbeiro era observado de cima, pelo Poetaalbatroz. Este fato é comprovado pelo verbo "descer" que se encontra no primeiro verso desta terceira parte. O eu-lírico se encontrava no espaço imenso, que é o próprio céu, logo podia olhar o navio por cima. A representação da águia pode ser entendida como o próprio eu-lírico, pois é ele que adentra o navio e é águia que desce do espaço imenso, com enunciado no seguinte verso: "Desce do espaço imenso, ó águia do oceano!“

Este fragmento revela ao leitor que o eu-lírico assume, metaforicamente, o papel de águia, uma vez que estava sobrevoando o navio, logo tinha uma visão de totalidade e não de singularidade. Em um segundo momento, esta águia, como já se sabe, representada pelo eu-lírico, aproxima-se do navio e enxerga a desumanização que lá está ocorrendo.

Entretanto, a primeira distância, marca da liberdade condoreira, é muito grande e há o pedido de que a aproximação se faça maior. Castro Alves, ao compor a terceira parte, trabalha com a utilização das reticências no segundo verso, recurso também utilizado no quarto e quinto versos desta estrofe, consentindo a estes, um aumento de emoção. Segundo os professores Faraco e Moura (1998, p.504) "as reticências tem a função básica de [...] indicar surpresa, dúvida, hesitação".

Retomando o segundo verso, "Desce mais... inda mais... não pode olhar humano/Como o teu mergulhar no brigue voador!", percebe-se uma característica relevante, a miscigenação do olhar animal e humano, assim, na composição, o olhar do eulírico é representado numa unificação com o animal de alto vôo, ou seja, a encarnação do próprio condoreirismo. Esta encarnação pode ser ressaltada pela utilização do verbo "ver" na primeira pessoa, “vejo”, utilizado no quarto verso, "Mas que vejo eu aí!... Que quadro d'amarguras!"

Sobre o veleiro de dois mastros adentra o olhar que inicia a constatação da visão de um local infernal. Neste "brigue voador", que não pára pacificamente para os olhos do eulírico, este encontra a representação do sofrimento, composto pela somatória de figuras tétricas, vilania, infâmia que juntas compõem um horroroso canto de morte.

Valendo-se do ponto de exclamação, já utilizado no primeiro, terceiro, quarto e quinto versos, a estrofe é fechada, por meio deste sinal de pontuação, com um misto de 
noções como o assombro e a indignação, uma vez que esta marcação gráfica possui, conforme Cereja e Magalhães (1999, p.317), a finalidade de "indicar estados emocionais como espanto, surpresa, dor, alegria, súplica [...]".

Neste momento, há o clamor a Deus, a fim de que Este, sendo um ser supremo dotado de todos os poderes, possa resolver a situação que, aos seus olhos, não é possível de ser sanada pela intervenção de mão humana. Tal afirmação é confirmada pelo fragmento do último verso da terceira parte, "Meu Deus! Meu Deus! Que horror! Neste momento há a duplicidade da frase "Meu Deus!", assim há uma redundância que denota o excesso de angústia que sente o eu-lírico ao se deparar com tamanha crueldade.

O diálogo entre a terceira e quarta partes de Navio negreiro: tragédia no mar com a obra Divina Comédia de Dante Alighieri é notória. Dante, em sua obra, visita o inferno, que para o autor é dividido em nove círculos. A cada círculo infernal visitado por Dante em companhia de Virgílio, o autor demonstra uma sucessão de mais crueldade, sofrimento e dor.

Na quarta parte do poema de Castro Alves, o eu-lírico adentra realmente o navio e começa a descrever detalhadamente cada um dos elementos que observa naquela embarcação. Logo no início da primeira estrofe o Poeta-albatroz já estabelece a ligação com Dante Alighieri:

\footnotetext{
Era um sonho dantesco... o tombadilho Que das luzernas avermelha o brilho.

Em sangue a se banhar.

Tinir de ferros... estalar de açoite...

Legiões de homens negros como a noite, Horrendos a dançar...
}

Lajolo e Campedelli (1988, p.103), a respeito do primeiro verso da quarta estrofe, ditam: "Pode-se considerar que, com este verso, abre-se a 'tragédia do Mar'. O tombadilho, portanto funciona como cenário dela. A primeira, segunda e terceira partes do poema são a introdução para o que se vai presenciar a partir de agora."

A estrofe é composta por meio de inúmeras descrições revelando que tudo aquilo que se vê é um "sonho dantesco". O adjetivo "dantesco", utilizado neste fragmento, proporciona, portanto, a relação dialógica com o inferno de Dante Alighieri. Este habitat dos mortos é produzido pelo poeta, com nove círculos infernais, os quais representam respectivamente: o rio Arqueronte no qual está localizado um barco que será responsável 
pela travessia das almas; o inferno propriamente dito; o círculo onde ficam as pessoas gulosas; o dos avarentos; o das pessoas que possuem a ira em seu coração; o círculo que contém os túmulos de fogo e os hereges; o dos violentos com Deus e dos contra a natureza, ou seja, os homossexuais; o círculo em que ficam aqueles que têm os maiores pecados e recebem as torturas maiores e, por fim, o nono círculo onde se encontram os grandes traidores como Judas, Brutus e Cassius que são devorados por Satanás em sua moradia.

A obra de Dante é recuperada claramente na última estrofe da quarta parte em que se nota a figura de Satanás como espectador de tudo aquilo que está acontecendo no navio e, não obstante, ainda, rindo. É possível perceber que este navio está, metaforicamente, representando o local onde reina o Diabo e que quanto mais nele se aprofunda, maiores são as crueldades presenciadas.

Manifesta, no segundo verso, está a cor vermelha que, entre muitos significados, é, também, a cor do sangue. No contexto em que esta cor está inserida revela-se ao leitor que os escravos se banham no próprio sangue, ou seja, percebe-se a hipérbole, a utilização da linguagem de maneira exagerada, uma vez que seria necessário muito sangue para que uma legião de homens se banhasse. No momento em que se utiliza o termo "legiões" denota-se que havia muitos homens, novamente, surgindo a questão hiperbólica no texto.

No quarto verso a sonoridade rompe por meio dos instrumentos de tortura revelada no verso "tinir de ferros e estalar de açoite". Este verso denuncia o maltrato aos escravos, pois os ferros e os açoites são lançados em direção ao corpo deles, gerando assim, um tratamento desumano.

$\mathrm{Na}$ primeira estrofe o eu-lírico descreve as luzes vermelhas e o brilho que elas provocam, metáfora do sangue dos subjugados. Logo em seguida, há a indicação do "tinir de ferros" do "estalar de açoites", ou seja, o som provocado pelos homens brancos nos negros escravos. Este som serve de músicas para os escravocratas, que observam seus prisioneiros bailando sobre o tombadilho. Entretanto, esta dança é antitética à vontade dos africanos, regidos pelo mando do açoite.

Na segunda estrofe a cena composta é mais cruel, nela passam a ter existência as mulheres descritas na tentativa de alimentar seus filhos, mas o único alimento que sai de suas "tetas" é o sangue, uma vez que sofreram tanto ao ponto deste alimento materno secar e não poderem prover sua prole. Neste fragmento a zoomorfização se faz presente já que os seios de uma mulher são referidos como tetas, nomenclatura imposta somente aos animais. Note-se: 
Negras mulheres, suspendendo às tetas

Magras crianças, cujas bocas pretas

Rega o sangue das mães:

Outras moças, mas nuas e espantadas,

No turbilhão de espectros arrastadas,

Em ânsia e mágoa vãs!

Há, ainda, a menção de que no navio outras pessoas estão, descritas estas como moças "nuas e espantadas". O adjetivo "nua" dá a estas moças a condição de ausência de proteção, tanto física quanto psicológica, entretanto o adjetivo "espantadas", mostra a qualificação de assustadas diante do cenário, que, talvez já identifique a possibilidade de um final trágico em suas vidas.

Estas mesmas moças estão envoltas "no turbilhão de espectros". Os espectros são os fantasmas presentes naquele tombadilho, e, não sendo fator o bastante a presença destes, os escravos estão cercadas por uma grande quantidade destes em alvoroço, o que reafirma a agonia vã destas personagens.

Na terceira estrofe da quarta parte, a ironia é revelada. A "orquestra" descrita é formada por homens brancos que espancavam os escravos, sendo que este conjunto de músicos, que impõem o ritmo ao navio, não se importava com toda dor que causava àquelas pessoas, fato exposto pelo verbo "rir", que evidencia o prazer que a prática do mau trato lhes propicia.

O instrumento utilizado pelos regentes das orquestras é a batuta, aqui metamorfoseado em chicote. No texto literário, os homens brancos divertem-se regendo os escravos que dançam ao som estridente do estalar do chicote somado ao "tinir de ferros".

A desumanização é trazida à tona nos seguintes versos: "Se o velho arqueja, se no chão resvala,/Ouvem-se gritos... o chicote estala./E voam mais e mais...". Conseqüentemente, é possível perceber que quanto mais se sofre menos se agüenta a dor, mas, ainda assim, estes escravos são forçosamente obrigados a dançar.

Para reafirmar a idéia posta, está claro que na quarta estrofe da quarta parte, o eulírico indica ao leitor que toda aquela multidão sofre sem cessar, eles não se agüentam em pé de tanta fome, pois estão fracos devido á falta de alimentação e nutrientes adequados que não lhes é proporcionado.

Presa nos elos de uma só cadeia,

A multidão faminta cambaleia,

E chora e dança ali!

Um de raiva delira, outro enlouquece, 
Outro, que martírios embrutece,

Cantando, geme e ri!

É notório que as pessoas estão delirando ou até mesmo enlouquecendo, pois não há o que fazer naquele navio, a não ser continuar sofrendo. O termo mártir, advindo do latim martyr, cujo significado é testemunha, traz a ideologia de uma pessoa que morre e sofre por sua opção religiosa, ou pelo simples fato de professar uma religião qualquer ou agir de maneira que esteja contraria a sua própria religião. No poema, os mátires são representados pelos escravos que sofrem por serem negros em uma sociedade que os escraviza.

$\mathrm{Na}$ quinta estrofe destaca-se a ordem que o capitão, regente da orquestra que enuncia, "manda a manobra", ou seja, que impinge com mais veemência o sofrer.

\footnotetext{
No entanto o capitão manda a manobra, E após fitando o céu que se desdobra,

Tão puro sobre o mar,

Diz do fumo entre os densos nevoeiros:

"Vibrai rijo o chicote, marinheiros!

Fazei-os mais dançar!..."
}

Fica claro que o único elemento puro naquele quadro de desgraças é o "céu que se desdobra", local tradicionalmente descrito como a moradia de Deus, no entanto mesmo o capitão "fitando" este céu, pede para que seus homens não parem de bater nos escravos, pede para que os façam a dançar ainda mais. Para estes regentes a divindade, mesmo representada pelo céu não significa nada.

Em meio a preces dos negros escravizados, surge a antítese de Deus. A figura de Satanás é utilizada para a conclusão da quarta parte. Ela aparece para apreciar e sorver todo o sofrimento. Tal qual na obra de Dante Alighieri, A divina comédia, o Diabo se encontra no final. Em Dante, o senhor do inferno está no mais cruel e último dos nove círculos, em Castro Alves, ele está no final da quarta parte, quando o poeta termina sua descrição da crueldade depois de abandonar o condoreirismo.

E ri-se a orquestra irônica, estridente. . .

E da ronda fantástica a serpente

Faz doudas espirais...

Qual um sonho dantesco as sombras voam!...

Gritos, ais, maldições, preces ressoam!

E ri-se Satanás!... 
Assim como Castro Alves representou via texto verbal o sofrimento do escravo e o tráfico negreiro, Sebastião Salgado dialoga com este tema, porém via texto imagético.

Sebastião Ribeiro Salgado é um fotógrafo brasileiro que se dedica a retratar a real situação das pessoas exploradas e sem espaço, presentes na sociedade. É um fotodocumentarista reconhecido mundialmente, uma vez que é representante especial da UNICEF. Seu portfólio é composto por inúmeras obras, tais como, Outras Américas, Sahel: um homem em pânico, Trabalhadores: uma arqueologia da era industrial, Exxodos e Retratos de Crianças do Exxodo.

Foi no livro fotográfico Trabalhadores: uma arqueologia da era industrial que Sebastião Salgado retratou o trabalho manual em diversas partes do mundo, e devido a este, entre outros trabalhos, que o fotógrafo ficou reconhecido como um fotodocumentarista de excelente qualidade.

Vale ressaltar uma diferença significativa na questão da terminologia entre fotodocumentarista e fotojornalista.

O fotojornalista está preocupado com os acontecimentos reais presente no universo social, muitas vezes fazendo-se passar por uma testemunha ocular da sociedade, mostrando aos constituintes desta os acontecimentos por meio da imagem, que antes só era possível por meio de textos verbais. Este profissional se baseia tanto na objetividade quanto na subjetividade e, no mais das vezes, no realismo de cada cena. Devido às guerras, a fotografia passou a tomar mais espaço na cobertura dos acontecimentos deixando, assim, os fatos mais próximos do leitor e muitas vezes mais doloridos, pois na maioria dos casos a imagem era chocante, pois retratava os dramas ocorridos nas guerras.

Segundo Jorge Pedro Souza (2004) o fotojornalismo põe o leitor a par de algumas situações as quais certamente ele não estaria presente, conseqüentemente, a fotografia pode representar uma aproximação entre o leitor e o fato ocorrido. Logo, o fotojornalista tem o compromisso de sair para obter imagens diariamente, pois suas representações fotográficas, certamente, serão foco dos acontecimentos do dia, mesmo que este não saiba o que vai capturar naquele determinado dia.

Em geral, este trabalho desenvolvido pelo fotojornalista possui uma vertente social sendo uma das formas mais comuns de documentário. Por meio das imagens obtidas, este profissional deseja mostrar temas humanos que, podem ou não sofrer a influencia da sociedade, como fome, miséria, trabalho escravo entre outros. Os fotógrafos deste ramo da 
fotografia tentam inúmeras vezes revelar as condições de determinadas pessoas, ou até mesmo selecionam uma parcela prejudicada da sociedade.

O fotodocumentarismo nasceu como sendo um retrato de viagens em busca de determinada etnias de locais específicos. Jorge Pedro Souza em seu ensaio Uma história crítica do fotojornalismo ocidental (2004) revela que a vontade de retratar um mundo em extinção era o início do surgimento desse ramo profissional embora as primeiras produções tenham sido consideradas sem muita emoção e sentimento. Com o passar do tempo, o trabalho do fotógrafo em registrar imagens com o intuito documental ganhou mais técnica e uma visão mais humana. O mesmo autor acredita que o trabalho de um fotodocumentarista possui uma intervenção social, pois os ensaios são, na maioria dos casos, uma busca do invisível na sociedade.

Em síntese:

\begin{abstract}
De uma forma ampla, o fotodocumentalismo pode reduzir-se ao fotojornalismo, uma vez que ambas as atividades usam, freqüentemente, o mesmo suporte de difusão (a imprensa) e têm a mesma intenção básica (documentar a realidade, informar, usando fotografias). Porém, e em sentido restrito, por vezes distingue-se o fotojornalismo do fotodocumentalismo pela tipologia de trabalho. Um fotodocumentalista trabalha em termos de projeto fotográfico. Mas essa vantagem raramente é oferecida ao foto-repórter, que, quando chega diariamente ao seu local de trabalho, raramente sabe o que vai fotografar e em que condições o vai fazer. (SOUZA, 2004, p.8)
\end{abstract}

As fotos documentaristas presente na obra Trabalhadores: uma arqueologia da era industrial, de Sebastião Salgado, são todas em preto e branco, o que denota uma crueldade maior no cenário apresentado, pois, segundo Flusser (2002, p.38) "O preto e o branco são situações ideais, situações limite. O branco é a presença de todas as vibrações luminosas e o preto é a ausência total."

Salgado faz o possível para registrar com um olhar solidário o trabalho de homens e mulheres, que mesmo não tendo as condições mínimas de trabalho, seguem fazendo o seu papel na sociedade, ainda que desvalorizado. O livro Trabalhadores: uma arqueologia da era industrial mostra ao leitor diversas atividades como, o trabalho de pesca do atum na Sicília, o trabalho em uma mina de enxofre na Indonésia, entre os quais surge o resultado do dificultoso trabalho realizado pelos brasileiros em Serra Pelada.

A região da Serra Pelada está localizada no estado do Pará e se tornou muito conhecida na década de 1970 e 1980 por uma procura incessante de ouro, também, ficou 
conhecida como o maior garimpo ao ar livre que já existiu no mundo. A localização de Serra Pelada exata é em Curiópolis, ao sul do estado do Pará.

Por meio da linguagem imagética fotográfica de Sebastião Salgado pode-se estabelecer um diálogo com poema de Castro Alves, uma vez que as duas formas de linguagem abordam de maneira distinta o mesmo assunto.

Tendo em vista uma das fotografias do conjunto selecionado, percebe-se que a visão do fotógrafo é posicionada do alto, podendo assim, remeter a visão condoreira de Navio negreiro: uma tragédia no mar. A primeira impressão que se tem ao observar a fotografia é de um aglomerado de pequenas coisas, sem uma forma

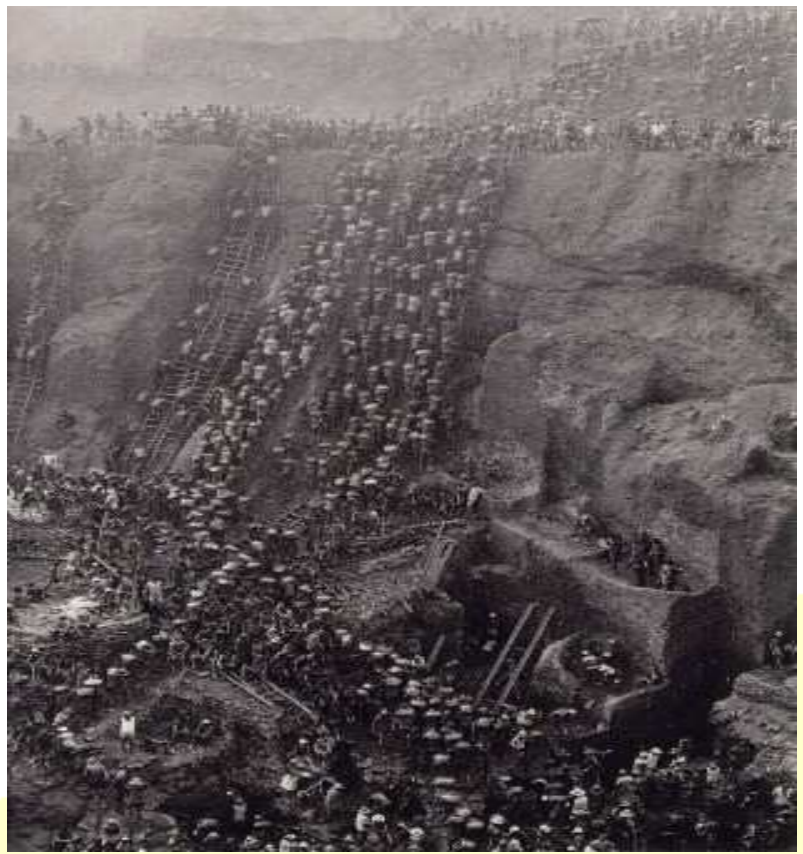

http://www.terra.com.br/sebastiaosalgado/ definida.

Valendo-se da teoria da Gestalt, pode-se buscar a pregnância da forma, a qual pressupõe que quanto melhor for a organização visual, melhor será a facilidade de compreensão. Evidentemente, o caminho oposto é correlato.

$\mathrm{Na}$ imagem de Salgado, condoreira, pois vista de um ângulo superior, as figuras humanas ficam ambíguas e não são evidentes ao primeiro olhar, tal qual a terceira parte do poema romântico.

Segundo Gomes Filho (2006, p.37) "quanto pior ou mais confusa for a organização visual da forma do objeto menor será seu grau de pregnância”, assim, menor o grau de compreensão, pois o leitor deve dedicar uma maior de tempo de observação, e este tempo

decorre, exatamente, porque as forças internas de organização da forma, agindo no sistema nervoso do observador, procuram achar a melhor estrutura perceptiva possível no objeto, permitindo a sua decodificação em alguma coisa mais clara e lógica, de modo a facilitar sua compreensão.

Ao dirigir o olhar mais profundamente à imagem de Salgado, nota-se que linhas circulares e diagonais compositoras da fotografia são em verdade pessoas, mas estes seres 
humanos não possuem rostos, deixando transparecer que não possuem individualidade, são simplesmente uma unidade. Esse amontoado de pessoa é retratado em Castro Alves pelo termo hiperbólico "legião", caracterizador daqueles escravos que também não possuíam uma individualidade. A presença das linhas circulares, irregulares e diagonais provoca no leitor uma tensão, uma vez que não há definição nítida do que se vê.

Outro elemento muito marcado nesta fotografia é fato de não haver uma harmonia. Segundo Gomes Filho (2004, p.56), “A desarmonia é reforçada pelo excessivo número de unidades formais que se transformam em poluição visual, traduzidos pelos diversos elementos irregulares, incoerentes e fragmentados."

Os diagonais presentes nesta imagem representam uma instabilidade, assim como afirma, Dondis (1999, p.60): “A direção diagonal tem referência direta com a idéia de estabilidade. É a formulação oposta, a força direcional mais instável, e, conseqüentemente, mais provocadora das formulações visuais. Seu significado é ameaçador e quase literalmente perturbador."

Outra característica que remete ao diálogo entre Navio negreiro: uma tragédia no mar e as fotografias de Serra Pelada é o fato da base da fotografia ser mais escura. Esta parte remete à palavra "dantesco" presente tanto no poema de Castro Alves quanto na obra de Dante Aligheri, já conhecido como o inferno, local de pouca luz. É possível notar que neste lugar não há a presença de vegetação, revelando o aspecto seco e sem vida. A presença do contraste entre o claro e o escuro gera "uma contraforça à tendência do equilíbrio absoluto, ele desequilibra, sacode, estimula e atrai a atenção." (GOMES FILHO, 2006, p.62) logo, pode-se dizer que a parte mais escura da fotografia atrai o olhar do leitor, logo para baixo.

Sabe-se que quanto menor o horizonte, mais tensão há na composição da imagem. No caso da fotografia em questão este elemento não se faz presente, deixando, assim, mais uma vez, a ansiedade penetrar no leitor. Este sentimento é causado pelo desequilibro proporcionado pela imagem, pois "as posições inclinadas concorrem para refletir e acentuar o desequilíbrio, ao mesmo tempo em que provocam sensação de movimento" (GOMES FILHO, 2006, p.61) 
$\mathrm{Na}$ imagem a seguir percebe-se, novamente, uma "legião" de homens amontoados tentando subir a serra, em busca de cumprir o próprio trabalho, mas em nenhum momento surge alguma característica que os individualize, tornando-os, assim, objetos e não seres humanos. Pode-se estabelecer uma relação com a terceira parte de Navio negreiro: uma tragédia no mar, pois a aproximação da imagem produzida por Salgado mostra muitos homens, uma vez mais, amontoados, no entanto desta vez a aproximação é mais trágica, pois se acredita que com esta aproximação seria possível ver detalhes aqueles homens, mas o que se vê, no entanto é mais uma vez corpos humanos juntos sem distinção que os individualize. Esta aproximação

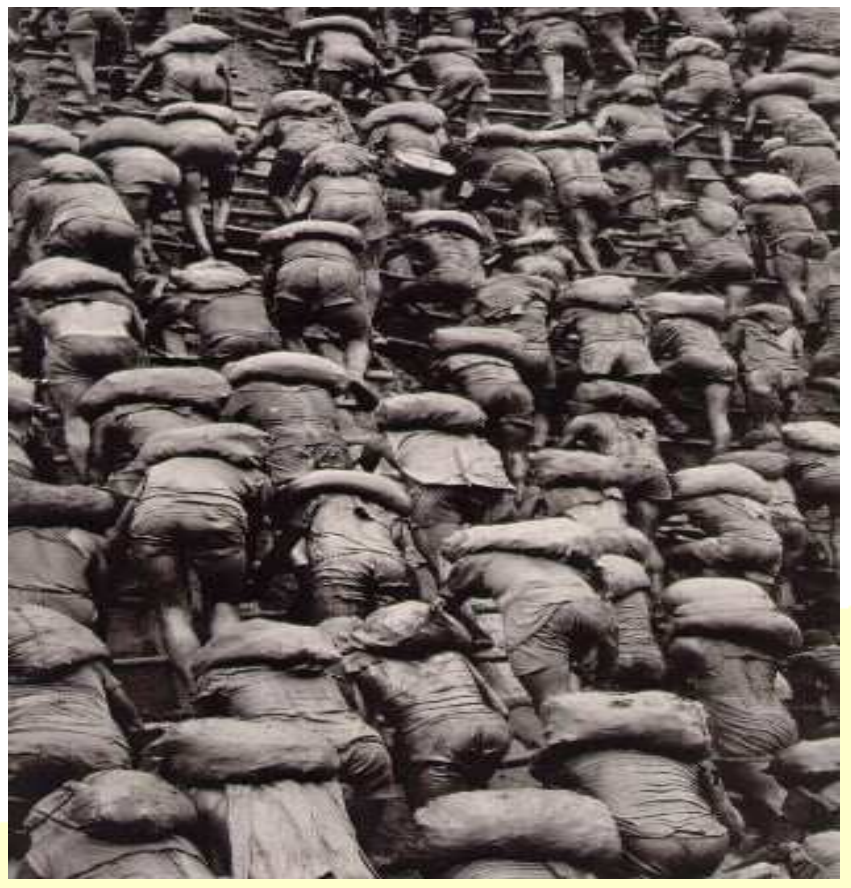

http://www.terra.com.br/sebastiaosalgado/ do olhar ocorre, em ambos os textos na tentativa de entender o que acontece com esses homens.

Quando Gomes Filho aborda a questão da configuração esquemática, destaca que "o observador não consegue identificar ou reconhecer o grupo ou qualquer pessoa dentro do grupo de maneira particular." (p.47).

$\mathrm{O}$ aspecto de fechamento, também é percebido nesta fotografia, sem a presença do horizonte, em que há uma "continuidade numa ordem estrutural definida" (GOMES FILHO, 2006, p.32). Ou seja, a imagem capturada por Salgado mostra ao leitor que esses homens, registrados em conjunto não possuem uma individualização, são apenas unidade quando no conjunto de seus corpos. Além desse fator, a continuidade se faz presente neste processo, uma vez que não uma quebra ou ruptura visual.

Esta fotografia possui um ritmo que pode ser percebido nas linhas diagonais que se instauram na imagem. Para Arnheim (2000, p.417),

A orientação oblíqua é provavelmente o recurso mais elementar e efetivo para se obter tensão dirigida. Percebe-se a obliqüidade espontaneamente como uma dinâmica que se afasta, ou em direção da estrutura espacial básica da vertical e horizontal, ou para longe da mesma. 
O dialogismo entre ambos os textos se estabelece no momento em que no texto verbal os escravos dançam porque estão sendo açoitados pelo chicote, no caso do texto imagético eles estão em pleno movimento, árduo, tentando subir a serra todos de uma só vez.

Pela composição a fotografia apresenta uma visão fechada uma vez que não há horizonte, a única direção que existe são as diagonais ascendentes gerando assim, conforme afirma Arnheim (2000), uma sensação de tensão para o leitor.

Ainda, analisando a mesma imagem nota-se que todos os quadrantes são tomados por homens, não há espaço livre para o direcionar do olhar do leitor, somente há, em todos os quadrantes da regra dos terços, homens trabalhando. Tal construção imagética proporciona um incomodo e uma tensão no leitor.

Em ambas as obras se podem perceber traços coincidentes em relação ao tema e à estrutura tratada. Castro Alves "disposto a lutar por meio da palavra" (LAJOLO e CAMPEDELLI, 1988, p.155) descreveu o funesto cenário do tráfico negreiro; assim sendo, desceu seu olhar condoreiro e colocou seus leitores dentro do cenário onde se realizava a tragédia no mar.

Sebastião Salgado, utilizando a fotografia, promoveu semelhante denúncia deixando seu leitor vivenciar o drama de Serra Pelada ora à distância e, em outros momentos, como se estivesse dentro do próprio garimpo.

O diálogo entre os textos verbal e imagético é não só possível como também necessário para se ampliar possibilidades de estudo entre linguagens.

\section{Referências Bibliográficas}

ALVES, Castro. Obra completa de Castro Alves. Rio de Janeiro, Nova Aguilar, 2002.

ARNHEIM, Rudolf. Arte e percepção visual: uma psicologia da visão criadora. São Paulo: Pioneira, 2000. (Biblioteca Pioneira de arte, arquitetura e urbanismo)

BAKHTIN, Mikhail. Estética da criação verbal. São Paulo: Martins Fontes, 1992. Marxismo e filosofia da linguagem: problemas fundamentais do método sociológico na ciência da linguagem. São Paulo: Hucitec, 1997. 
BARROS, Diana Luz Pessoa de e FIORIN, José Luiz. Dialogismo, polifonia, intertextualidade. São Paulo: EDUSP, 1999.

CAMPEDELLI, Samira Youssef e SOUZA, Jesus Barbosa. Literaturas brasileira $e$ portuguesa: teoria e texto. São Paulo: Saraiva, 2000.

CEREJA, Willian Roberto e MAGALHÃES, Thereza Cochar. Gramática reflexiva: texto, semântica e interação. São Paulo: Atual, 1999.

DONDIS, Donis A. Sintaxe da linguagem visual. São Paulo: Martins Fontes, 1991.

FARACO, Carlos Emílio e MOURA, Francisco Marto. Gramática. São Paulo: Saraiva, 1998.

FLUSSER, Vilém. Filosofia da caixa preta: ensaios para uma futura filosofia da fotografia. Rio de Janeiro: Relume Dumará, 2002.

GOMES, João filho. Gestalt do Objeto: Sistema de Leitura visual de Forma. São Paulo:

Escrituras, 2006.

GUIMARÃES, Alexandre Huady Torres. A documentação fotográfica da violência como um recurso para a reflexão educacional. 2001. Dissertação (Mestrado) - Universidade Presbiteriana Mackenzie, São Paulo, 2001.

KRISTEVA, Julia. Introdução à semanálise. São Paulo: Perspectiva, 2005. (Debates)

LAJOLO, Marisa e CAMPEDELLI, Samira Youssef. Literatura comentada: Castro Alves.

São Paulo: Abril Cultural, 1988.

MANGUEL, Alberto. Lendo imagens: uma história de amor e ódio. São Paulo: Companhia das Letras, 2001.

SALGADO, Sebastião Ribeiro. Trabalhadores: uma arqueologia da era industrial. São Paulo, Companhia das Letras, 2007. http://www.terra.com.br/sebastiaosalgado. Acessado em 28.08.2007.

SOUZA, Jorge Pedro. História crítica do jornalismo ocidental. Florianópolis: Grifos, 2004. 